\title{
Clinical presentation and functional prognosis in syndrome $\mathrm{X}$
}

\author{
Anoop Chauhan, Paul A Mullins, Suren I Thuraisingham, Michael C Petch, \\ Peter M Schofield
}

\begin{abstract}
Objectives-To assess the effect of clinical presentation on functional prognosis in patients with syndrome $X$.

Design-A prospective study. Patients with syndrome $X$ presenting with unstable angina and stable angina were followed up with a questionnaire to examine their functional state.

Patients-41 patients with syndrome $X$ and unstable angina and 41 patients with syndrome $X$ and stable angina. Syndrome $X$ was defined as typical anginal chest pain, a positive exercise test, and normal coronary angiogram.
\end{abstract}

Setting-Regional cardiothoracic centre. Results-The mean follow up time was 36 (range 20-51) months for the unstable angina group and 35 (range 19-51) months for the stable angina group. No patient was lost to follow up in either group. At follow up 28 patients in the unstable angina group were pain free compared with 15 patients in the stable angina group $(p=0.008)$. Seven patients in the unstable angina group had further hospital admission with chest pain after the cardiac catheterisation compared with 12 patients in the stable angina group (NS). Seven patients in the unstable angina group believed that they had heart disease compared with 27 in the stable angina group $(p<0.001)$. 26 patients in the unstable angina group but only eight patients in the stable angina group were unlimited in their physical activity $(p<0.001)$. 12 patients in the unstable angina group compared with 27 patients in the stable angina group were unable to work normally because of chest pain $(p<0.001)$. The mean (SD) duration of symptoms before cardiac catheterisation was $7.9(4 \cdot 7)$ months in the unstable angina group and $13.4(5.6)$ months in the stable angina group $(p<0.001) .10$ patients in the unstable angina group and 24 patients in the stable angina group still attended hospital outpatient clinics because of chest pain $(p=0.004) .16$ patients in the unstable angina group and 29 patients in the stable angina group were still taking regular antianginal medication $(p<0.001)$. Conclusions-Patients with syndrome $X$ who present with unstable angina have a significantly better functional prognosis than those presenting with symptoms of stable angina. This may reflect differences in underlying pathophysiological mechanisms.

(Br Heart f 1993;70:346-351)

Most of the clinical manifestations of ischaemic heart disease are due to a fixed or dynamic obstruction of epicardial coronary arteries. In more than $10 \%$ of patients undergoing coronary angiography for the assessment of chest pain, however, the coronary angiogram is normal. ${ }^{1-3}$ Also, about $10 \%$ of patients referred for cardiac catheterisation with the diagnosis of unstable angina have normal coronary angiograms. ${ }^{45}$ These patients are said to have angina pectoris with normal coronary angiograms or Syndrome $\mathrm{X}$. It is now recognised that syndrome $\mathrm{X}$ is a heterogeneous syndrome that encompasses different pathophysiological entities. ${ }^{67}$ It has been shown by many studies that patients with chest pain and normal coronary arteries have a normal long term life expectancy..$^{8-10}$ The same studies have also indicated, however, that there is a considerable residual morbidity with medical, economic, and social consequences. Studies of functional state have shown that many patients with syndrome $\mathrm{X}$ continue to remain significantly limited in activity despite reassurance. ${ }^{1112}$ Differences in the functional state of patients with syndrome $\mathrm{X}$ who present with unstable angina compared with those who present with stable angina have not been reported previously. We investigated the hypothesis that patients with syndrome $\mathrm{X}$ who present with unstable angina may have a different functional prognosis than those presenting with stable symptoms due to differences in underlying pathophysiological mechanisms. This may allow the identification of a subset of patients with a worse functional prognosis.

\section{Patients and methods}

PATIENTS

The functional state of 41 patients with syndrome $\mathrm{X}$ who presented to Papworth Hospital with unstable angina (unstable angina group) and 41 patients with syndrome $\mathrm{X}$ who presented with stable angina (stable angina group) was examined prospectively. Patients were recruited into the study during the period 1988 to 1991 . 
PATIENT SELECTION

Consecutive patients with syndrome $\mathrm{X}$ presenting with unstable angina were approached for inclusion in the study. All patients gave full informed consent. Each patient then underwent oesophageal function studies. Patients in whom these were abnormal were excluded. The remaining patients were then matched with patients with syndrome $\mathrm{X}$ presenting with stable angina who had also undergone oesophageal function studies to exclude patients with oesophageal abnormalities.

During the study recruitment period 47 patients with syndrome $\mathrm{X}$ presented with unstable angina. This constituted $12 \%$ of the total number of patients presenting with syndrome X. Forty six of these consented to be included in this study. Five $(11 \%)$ had an abnormality on oesophageal function tests and were therefore excluded from the study. A total of 50 patients with syndrome $\mathrm{X}$ presenting with stable angina were investigated by oesophageal function studies. Nine (18\%) had an abnormal oesophageal manometry and were therefore excluded. The remaining 41 were matched to patients with syndrome $\mathrm{X}$ and unstable angina for the follow up study.

\section{UNSTABLE ANGINA GROUP}

Because of their symptoms, these patients with unstable angina were referred from other hospitals in the region for urgent coronary angiography. The cardiac enzymes had been normal in all patients. There were 20 men and 21 women in this group.

\section{STABLE ANGINA GROUP}

These patients had been referred initially to the outpatient clinic with a diagnosis of angina. Their symptoms had continued despite antianginal medication and they were subsequently electively admitted for cardiac catheterisation. There were 16 men and 25 women in this group.

\section{DEFINITION OF SYNDROME $\mathrm{X}$}

Syndrome $\mathrm{X}$ was defined as typical anginal chest pain, a positive exercise test, and normal coronary arteries on angiography as reviewed by two independent observers. All patients underwent an exercise test with a standard Bruce protocol after all antianginal medication had been stopped for a minimum of three days. In all patients the exercise test was performed after the cardiac catheterisation and only those patients with a positive exercise test were included in the study. The exercise test was considered to be positive if there was horizontal or downsloping ST segment depression of $>1 \mathrm{~mm}$ for $80 \mathrm{~ms}$ after the J point. All patients had a normal left ventricular function as judged from the echocardiogram and left ventricular angiogram. The left ventricular end diastolic pressure was normal in all patients. There was no evidence of muscle bridging on coronary angiography.

DEFINITION OF UNSTABLE ANGINA

Unstable angina is a descriptive term for a spectrum of acute myocardial syndromes that lie clinically between stable angina and myocardial infarction. The term, as it is used in clinical practice, is not precisely defined and many complex classifications have been proposed based on clinical and angiographic criteria. ${ }^{1314}$ In this study unstable angina was defined as (a) new angina of one to two months duration occurring at low work loads or rest; $(b)$ crescendo angina defined as a noticeable increase in the frequency or severity of previously stable angina; and (c) pain at rest with electrocardiographic evidence of ischaemia but without evidence of myocardial infarction. These categories are not mutually exclusive. The category of pain at rest would include some patients with previously mild angina and a noticeable increase in symptoms (crescendo angina) and also patients with previously severe angina and a slight increase in symptoms.

\section{ECHOCARDIOGRAPHY}

All patients underwent echocardiographic assessment. $\mathrm{M}$ mode and cross sectional assessments of the left ventricular posterior wall and septal thickness were made.

\section{BLOOD ANALYSIS}

Blood samples were taken for full blood count, serum urea and electrolytes, and fasting lipids on the morning of their cardiac catheter study.

\section{OESOPHAGEAL STUDIES}

All patients underwent oesophageal manometry and 24 hour $\mathrm{pH}$ studies after their cardiac catheterisation to exclude an oesophageal cause for chest pain.

\section{EXCLUSION CRITERIA}

Patients with even minimal coronary artery irregularities, hypertension, diabetes mellitus, clinical or echocardiographic evidence of left ventricular hypertrophy or valvar heart disease, and abnormalities of oesophageal function were excluded from the study. We also excluded those patients who had a left bundle branch block on the resting electrocardiogram or developed one during the exercise test.

\section{CARDIAC CATHETERISATION}

All patients underwent left heart catheterisation through the percutaneous femoral approach and left ventriculography and coronary arteriography were performed. An altered perception of pain has been previously reported in patients with syndrome X.15-17 It was noted during the cardiac catheterisation, whether manipulations of catheters in the aortic root and the left ventricle, and injection of a $5 \mathrm{ml}$ bolus of contrast medium into the left and right coronary arteries, produced any chest pain.

\section{FOLLOW UP}

Consecutive patients who satisfied the relevant criteria were placed in either the unstable angina or stable angina group depending on their presentation. The patients 
Table 1 Patient responses

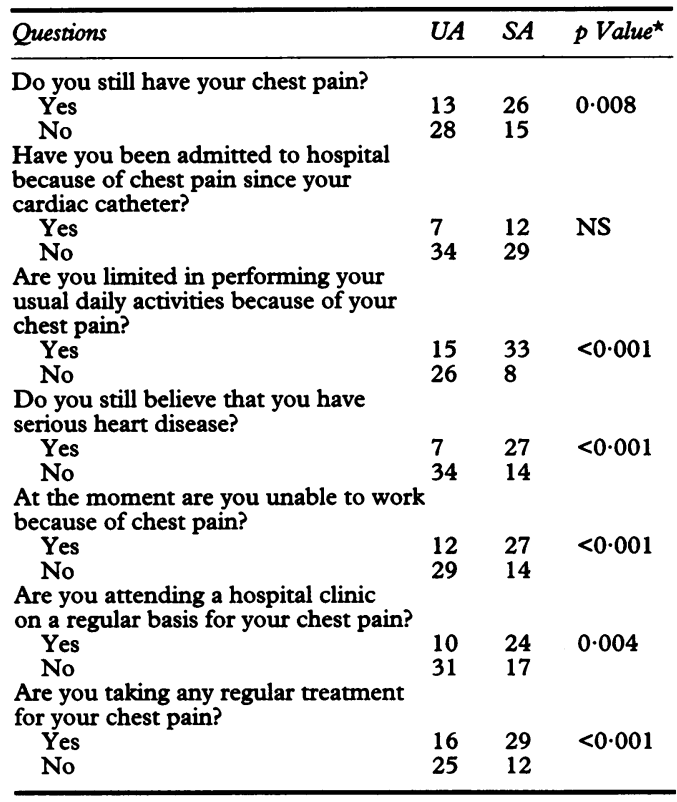

${ }^{\star} \chi^{2}$ analysis, UA, unstable angina group; SA, stable angina group.

were followed up at six monthly intervals with a questionnaire (table 1). The questionnaire inquired about the patient's symptoms, limitations, and work capacity. The final assessment was performed in December 1992.

Patients were reassured after the cardiac catheterisation that their heart and coronary arteries were normal. It was explained to them that an excellent prognosis was expected although they might continue to experience chest pain. It was emphasised to them that although their heart was normal we still believed in their symptoms and at no time was it suggested that their pain was psychosomatic in nature. The referring physicians were informed of the normal findings. Patients were also informed that no restriction on their physical activity was necessary and they should try to lead a normal life.

\section{STATISTICAL ANALYSIS}

The data were compared by $\chi^{2}$ analysis, Fisher's exact test, and Student's $t$ test as appropriate.

\section{Results}

Table 2 shows relevant patient information.

Table 2 Patient variables

\begin{tabular}{lll}
\hline & $\begin{array}{l}\text { Unstable angina } \\
\text { group } \\
(n=41)\end{array}$ & $\begin{array}{l}\text { Stable angina } \\
\text { group } \\
(n=41)\end{array}$ \\
\hline Weight $(\mathrm{kg})$ & $77 \cdot 3(11 \cdot 3)$ & $72 \cdot 5(10 \cdot 8)$ \\
Smokers & 18 & 15 \\
Hb (g/dl) & $14 \cdot 1(1 \cdot 4)$ & $13 \cdot 8(1 \cdot 1)$ \\
Plt $(10-9)$ & $278(46)$ & $287(59)$ \\
PCV $(1 / 1)$ & $0 \cdot 42(0 \cdot 04)$ & $0 \cdot 40(0 \cdot 04)$ \\
ESR $(\mathrm{mm} / \mathrm{h})$ & $11(10)$ & $9(6)$ \\
Urea $(\mathrm{mmol} / \mathrm{l})$ & $6 \cdot 0(0 \cdot 9)$ & $6 \cdot 2 \cdot(0 \cdot 8)$ \\
Glucose $(\mathrm{mmol} / \mathrm{l})$ & $4 \cdot 6(0 \cdot 7)$ & $4 \cdot 9(1 \cdot 0)$ \\
Creatinine $(\mu \mathrm{mol} / \mathrm{l})$ & $111(15)$ & $102(17)$ \\
Cholesterol $(\mathrm{mmol} / \mathrm{l})$ & $6 \cdot 1(0 \cdot 8)$ & $5 \cdot 9(0 \cdot 3)$ \\
LVEDP (mm Hg) & $9(1 \cdot 0)$ & $8(0 \cdot 8)$ \\
Previous hysterectomy & 2 & 6 \\
\hline
\end{tabular}

Values are given as means (SD) where appropriate. ESR, erythrocyte sedimentation rate; $\mathrm{Hb}$, haemoglobin; LVEDP, left ventricular end diastolic pressure; $\mathrm{PCV}$, packed cell volume; Plt, platelets.
Table 3 Exercise test data

\begin{tabular}{|c|c|c|}
\hline & $\begin{array}{l}\text { Unstable angina } \\
\text { group } \\
(n=41)\end{array}$ & $\begin{array}{l}\text { Stable angina } \\
\text { group } \\
(n=41)\end{array}$ \\
\hline $\begin{array}{l}\text { Resting HR (beats/min) } \\
\text { Time to } 1 \mathrm{~mm} \mathrm{ST} \\
\text { depression (min) }\end{array}$ & $\begin{array}{l}86(14) \\
8 \cdot 3(2 \cdot 0)\end{array}$ & $\begin{array}{l}82(13) \\
8.0(1.9)\end{array}$ \\
\hline $\begin{array}{l}\text { RPP at end of stage } 1 \\
\text { RPP at peak exercise } \\
\text { Maximum exercise } \\
\text { duration (min) }\end{array}$ & $\begin{array}{r}325(3521) \\
26235(4470) \\
9 \cdot 0(2 \cdot 6)\end{array}$ & $\begin{array}{r}19986(3724) \\
25980(4190) \\
8 \cdot 8(2 \cdot 4)\end{array}$ \\
\hline
\end{tabular}

Values are given as means (SD). Differences are not significant. HR, heart rate; RPP, rate-pressure product.

In the unstable angina group the mean age was 47 (range 28-69) years and the mean follow up time was 36 (range 20-51) months. In the stable angina group the mean age was 46.4 (range 29-68) years and the mean duration of follow up was 35 (range 19-51) months. Fifty one percent were women in the unstable angina group compared with $61 \%$ in the stable angina group. There was no significant difference in the number of smokers between the two groups.

\section{EXERCISE TEST DATA}

Table 3 shows that there was no significant difference in the mean duration of exercise, time to $1 \mathrm{~mm}$ ST segment depression, and the rate pressure product (heart rate $\times$ systolic pressure) at peak exercise between the two groups. The resting heart rates of the two groups were also similar.

\section{FUNCTIONAL FOLLOW UP}

No patient was lost to follow up in either group. There were no deaths. The mean (SD) duration of symptoms before cardiac catheterisation was $7.9(4.7)$ months in the unstable angina group and 13.4 (5.6) months in the stable angina group $(p<0.001$, Student's $t$ test). Table 1 shows the results of the responses to the follow up questionnaire. Significantly more patients were completely pain free in the unstable angina group than in the stable angina group (28 $v 15 ; \mathrm{p}=0.008)$. Seven patients in the unstable angina group and 12 patients in the stable angina group had further hospital admissions with chest pain but this difference was not statistically significant. Details of these admissions were obtained and showed that none were associated with myocardial infarction. Repeat coronary angiography was performed in four of these patients (one in the unstable angina group and three in the stable angina group). This again showed normal coronary arteries.

Only seven patients in the unstable angina group but 27 patients in the stable angina group still believed that they had serious heart disease $(p<0.001)$. Twenty six patients in the unstable angina group but only eight patients in the stable angina group were unlimited in their physical activities $(p<$ 0.001 ). Twelve patients were unable to work normally because of their chest pain in the unstable angina group compared with 27 in the stable angina group $(p<0.001)$. Significantly more patients were still attending a medical out patient clinic for their chest 
Table 4 Use of antianginal drug

\begin{tabular}{lcll}
\hline & $\begin{array}{l}\text { Stable } \\
\text { angina } \\
\text { group }\end{array}$ & $\begin{array}{l}\text { Unstable } \\
\text { angina } \\
\text { group }\end{array}$ & $p$ Value* \\
\hline Nitrates & 3 & 11 & 0.02 \\
$\beta$ Blockers & 6 & 9 & NS \\
Calcium antagonists & 15 & 28 & 0.004 \\
\hline
\end{tabular}

^Fisher's exact test.

pain in the stable angina group compared with the unstable angina group (24 $v 10$; $\mathrm{p}=0.004)$.

\section{ANTIANGINAL MEDICATIONS}

Table 4 shows that 16 patients in the unstable angina group and 29 in the stable angina group were still taking antianginal medications $(p<0.001)$. Patients in the stable angina group were taking significantly more nitrates $(p=0.02)$ and calcium antagonists $(p$ $=0.004)$. There was, however, no significant difference in the use of $\beta$ blockers between the two groups.

\section{CHEST PAIN AT CARDIAC CATHETERISATION}

Thirty two patients in the stable angina group but only 12 patients in the unstable angina group experienced their usual chest pain at the time of their cardiac catheterisation on catheter manipulation or intracoronary injection of a $5 \mathrm{ml}$ bolus of contrast $(p<0.001)$. At follow up, 24 (71\%) of stable angina and eight $(67 \%)$ of these unstable angina patients remained considerably limited by their symptoms (NS).

\section{Discussion}

The term syndrome $\mathrm{X}$ was coined by Kemp 20 years ago to define patients presenting with chest pain and normal epicardial coronary arteries. ${ }^{18}$ Investigations over the past two decades have not found a specific cause for this syndrome. Many explanations have been put forward to explain it, including small vessel abnormalities, ${ }^{19}$ coronary artery spasm, ${ }^{20}$ cardiomyopathy, ${ }^{21}$ metabolic abnormalities, ${ }^{22}$ misinterpretation of the coronary angiograms, ${ }^{23}$ impaired coronary flow reserve, ${ }^{2425}$ oxyhaemoglobin dissociation defects, ${ }^{26}$ psychosomatic factors, ${ }^{27,28}$ altered pain perception, ${ }^{17-19}$ increased sympathetic drive, ${ }^{29-31}$ and endothelial dysfunction. ${ }^{32}$ As investigations have accumulated more information, the syndrome has become ever more confusing. All attempts to find a single pathophysiological mechanism responsible for the clinical presentations and long-term course of syndrome $\mathrm{X}$ have been confounded. It is now acknowledged that syndrome $\mathrm{X}$ probably encompasses several pathophysiological diseases.

Previous studies of functional disability have shown that about three quarters of patients with syndrome $X$ continue to see a physician, about half regard their life as significantly disabled, about half remain or become unemployed. ${ }^{11} 1233$ About $75 \%$ report residual chest pain at follow up. Only about one third to a half are reassured that they do not have serious heart disease. None of these studies has, however, adequately differentiated between patients with syndrome $\mathrm{X}$ with unstable angina and those with stable angina.

Our study has shown significant differences between the two presentations of syndrome $\mathrm{X}$. The findings in the stable angina group are similar to the other long-term studies. ${ }^{11} 1233$ It is clear, however, from the results that the unstable angina group is behaving differently. Patients with syndrome $\mathrm{X}$ presenting with unstable angina have an appreciably shorter duration of symptoms before their cardiac catheterisation. Many more of these patients are pain free at follow up, are working normally, and are unlimited in their physical activity. The patients with unstable angina are also less likely to be taking antianginal medications and attending hospital follow up clinics.

Previously, long-term follow up studies have shown that the incidence of subsequent myocardial infarction and sudden cardiac death in patients with chest pain and normal coronary arteries is very low. ${ }^{1834}$ Our study also confirms the good prognosis in patients with syndrome $X$. There were no deaths and no patients had a myocardial infarction over the follow up period.

Studies of oesophageal function had excluded patients from the study with abnormalities of the oesophagus which could have been the source of chest pain in some patients with syndrome $X$. The age difference between the two groups was not significant. Separate analysis of the functional capabilities by sex did not show any difference between the men and women. As the underlying pathophysiology may differ in the three subgroups of patients classified as having unstable angina the data were analysed to detect any difference in functional outcome between the subgroups. There were no significant differences.

The duration of symptoms before cardiac catheterisation was shorter in the unstable angina group. This probably reflects a clinical bias towards earlier referral and investigation of patients thought to have unstable angina. Patients with symptoms that are stable are more likely to be managed by drug treatment in the first instance and further investigations are only performed when the symptoms fail to settle.

It is reasonable to hypothesise that just as different subgroups with different underlying pathophysiological mechanisms many comprise syndrome $\mathrm{X}$, patients presenting with unstable angina and stable angina may have a different functional prognosis due to differences in the underlying mechanisms responsible for the symptoms. Any attempt at this stage to explain this difference is speculative as the patients in this study have not been investigated further to assess the presence of abnormal coronary flow reserve, epicardial coronary hyperreactivity, or evidence of variations in sympathetic activity. The results of our study, however, suggest that differences 
in perception of cardiac pain may be important in finding the functional outcome. Altered perception of painful stimuli has been reported in patients with syndrome $X$. This may heighten the perception of anginal chest pain in these patients. ${ }^{15-17}$ We have also shown previously that patients with syndrome $\mathrm{X}$ commonly have an exaggerated cardiac sensitivity compared with patients with coronary artery disease or valvar heart disease with their typical pain provoked by intracardiac stimulation in the absence of ischaemia. ${ }^{35}$ In this study there was a significant difference in the number of patients reporting their usual chest pain at the time of their cardiac catheterisation in the two groups with more patients complaining of pain in the stable angina group (32 $v 12, \mathrm{p}<0.001$ ). This suggests that many more patients presenting with stable angina have abnormal cardiac nociception and this may contribute to the differences in the functional prognosis between the two groups. Also, in both groups, most patients who reported chest pain at the time of their catheterisation continued to have symptoms at follow up suggesting that patients who may have an altered pain perception tend to remain more symptomatic and functionally limited regardless of their clinical presentation. This is the first report of long-term functional prognosis in patients thought to have altered perception of pain and our results lend further support to the theory that some patients with syndrome $\mathrm{X}$ may have an altered perception of pain. This study has also shown, for the first time, a difference in the prevalence of an abnormal perception of pain based on clinical presentation in syndrome $\mathrm{X}$. It is tempting to postulate that the fundamental difference in the underlying pathophysiological mechanism of the two presentations of syndrome $\mathrm{X}$ was the prevalence of an abnormal cardiac nociception. The mechanisms that initiate pain in patients with syndrome $\mathrm{X}$ are not known but may include changes in heart rate, rhythm, contractility, or loading conditions. It may be that a lowered pain threshold in the stable angina group leads to chest pain as a result of these trigger factors more often and for longer causing their considerable functional morbidity.

Recently Rosano et al have suggested that the pathogenesis of syndrome $\mathrm{X}$ in women may be due to a generalised alteration of vasomotor control, including dysfunction of the coronary microcirculation secondary to ovarian hormonal deficiency. ${ }^{36}$ In their study of 99 patients with syndrome $\mathrm{X}, 78$ were women, and $35(44.9 \%)$ had had hysterectomies. They further investigated 30 women with symptoms and signs of ovarian hormonal deficiency and found them to be severely hypooestrogenic. In our study only two of the 21 women in the unstable angina group and six of the 25 women in the stable angina group had undergone a hysterectomy at the time of their final follow up. We have not specifically looked for symptoms of oestrogen deficiency and have not measured oestrogen concentrations in our study therefore we cannot comment on the oestrogen state of all the women patients. It is clear, however, that the number of women with a hysterectomy in our study is considerably lower (eight out of $46,17 \%$ ) than that reported by Rosano et al, and is in fact similar to that of the general population $(8 \%-12 \%) .{ }^{36}$

An increased sympathetic drive has also been suggested in patients with syndrome $\mathrm{X}$ by several studies. ${ }^{29-31}$ The resting heart rate was similar in the two groups in our study. Also, the time to $1 \mathrm{~mm}$ ST segment depression, mean exercise duration, and the rate pressure product at the end of stage one and at peak exercise were similar in the two groups. This suggests that the sympathetic drive was not significantly different between the two groups and that the functional differences found in our study are unlikely to be due to significant differences in the sympathetic drive. We did not, however, perform 24 hour ambulatory electrocardiographic recordings and did not measure plasma catecholamine concentrations to study the specific role of the sympathetic nervous system as this was beyond the scope of our study.

There is little objective evidence about the effect of cardiac medications in patients with syndrome X. Most patients in all long-term studies continue to report chest pain and take cardiac medications so there is unlikely to be a large drug effect. There are some reports that suggest that propranolol may reduce pain. ${ }^{1}{ }^{10} 37$ Accordingly, $\beta$ blockers were found to be the most effective drugs in these studies. It is interesting to note that in our study there was no significant difference in the use of $\beta$ blockers between the two groups. The use of calcium antagonists and oral nitrates was significantly more common in the stable angina group. The class of drugs used most commonly in both groups was the calcium antagonists. The use of antianginal drugs in our study was significantly higher in the stable angina group, which was also more limited functionally. This difference in the use of antianginal medications probably reflects the symptomatic improvement in the unstable angina group. Clearly, patients will tend to use antianginal drugs less if they feel better and get less chest pain. This may not, however, imply a remission of the underlying disease process. Indeed, Borghi et al have shown in a preliminary study describing the longterm clinical course of syndrome $\mathrm{X}$, that despite complete resolution of symptoms most patients still have ST depression and reversible perfusion abnormalities during exercise. ${ }^{38}$

It is well recognised that patients with chest pain and normal coronary angiograms, even if defined by a positive exercise test as syndrome $\mathrm{X}$, are a heterogeneous population with regard to the possible underlying pathophysiological cause of their chest pain. We did not assess the patients in this study by nuclear perfusion imaging or coronary flow reserve studies. The possibility that there may 
have been significant differences between the two groups in terms of an impaired coronary flow reserve cannot be excluded.

Although the good long-term prognosis in patients with syndrome $\mathrm{X}$ is not in doubt, it is also clear that there remains a significant functional disability in many patients. It has been considered previously that syndrome $\mathrm{X}$ does not represent a clinical entity but is rather a mix of unrelated conditions and the various components of this mix cannot be separated easily by clinical features alone. ${ }^{34} 39$ This study has shown for the first time that the clinical presentation of patients with syndrome may predict outcome with regard to their functional prognosis. In this study patients with syndrome $\mathrm{X}$ who presented with symptoms suggestive of unstable angina had a better functional prognosis than those patients with syndrome $\mathrm{X}$ who presented with symptoms of stable angina. Given the heterogeneous nature of syndrome $\mathrm{X}$ these differences may be due to different underlying pathophysiological mechanisms in the two groups. A higher prevalence of an abnormal cardiac nociception in the stable angina group may be responsible for their worse functional prognosis. The findings of our study provide new clues about syndrome $\mathrm{X}$ that may help our understanding of this fascinating entity.

Dr A Chauhan is a British Heart Foundation junior research fellow.

1 Kemp HG, Vokonas PS, Cohn PF, et al. The anginal syndromes associated with normal coronary arteriograms: report of a six year experience. $A m \mathcal{F ~ M e d}$ 1973;54:735-42

2 Proudfit WL, Shirley EK, Jones FM. Selective cine coronary arteriography: correlation with clinical findings in 1000 cases. Circulation 1986;33:901-10.

3 Dart AM, Alban Davies $\mathbf{H}$, Dalal J, Ruttley $\mathbf{M}$ Henderson AH. 'Angina' and normal coronary arteriograms. Report of a six year experience. Am $f$ Med ograms. Report

4 Plotnick GD, Greene HL, Carliner HL, Becker LC, Fisher ML. Clinical indicators of left main coronary artery disease in unstable angina. Ann Intern Med 1979;91:149-53.

5 Alison HW, Russell RO Jr, Mantle JA, Kouchoukos NT, Moraski RE, Rackleu CE. Coronary anatomy and arteriography in patients with unstable angina pectoris. Am 7 Cardiol 1978;41:204-9.

6 Maseri A, Crea P, Kaski JC, Crake T. Mechanisms of angina pectoris in syndrome X. $\mathcal{F} \mathrm{Am}$ Coll Cardiol 1991;17:499-506.

7 Cannon RO, Camici PG, Epstein SE. Pathophysiological dilemma of syndrome $\mathrm{X}$. Circulation physiological dilem

8 Papanicolaou MN, Califf RM, Hlatky MA, et al. Prognostic implication of angiographically normal and insignificantly narrowed

9 Isner JM, Salem DN, Banas JS, et al. Long term clinical course of patients with normal coronary arteriography: follow-up study of 121 patients with normal or nea normal coronary arteriograms. Am Heart $\mathcal{f} 1981 ; 102$ : 645-55.

10 Day LJ, Sowton E. Clinical features and follow-up of patients with angina and normal coronary arteries. Lancet 1976;2:334-7.

11 Lavey EB, Winkle RA. Continuing disability of patients with chest pain and normal coronary arteriograms. fournal of Chronic Diseases 1979;32:191-6.

12 Ockene IS, Shay MJ, Albert JS, Weiner BH, Dalen JE. Unexplained chest pain in patients with normal coronary arteriograms. $N$ Engl f Med 1980;303:1249-52.
13 Plotnick G. Unstable angina: a clinical approach. New York: Futura, 1985:11-7.

14 Maseri A. Pathogenetic classification of unstable angina as a guideline to individual patient management and proga guideline to individual patient manageme

15 Turiel M, Galassi AR, Glazier J, Kaski JC, Maseri A Pain threshold and tolerance in women with syndrome $\mathrm{X}$ and women with stable angina pectoris. $\mathrm{Am} \mathcal{F} \mathrm{Cardiol}$ 1987;60:503-7.

16 Shapiro LM, Crake T, Poole-Wilson PA. Is altered cardiac sensation responsible for chest pain in patients with normal coronary arteries? Clinical observation during catheterisation. $B M \Im$ 1988;296:170-1.

17 Cannon RO, Quyyumi AA, Schenke WH, Fananapazir L, Tucker EE, Gaughan AM, et al. Abnormal cardiac sensitivity in patients with chest pain and normal coronary sitivity in patients with chest pain and normal

18 Kemp HG. Left ventricular function in patients with the anginal syndrome and normal coronary arteriograms. am $₹$ Cardiol 1973;32:375-6.

19 Mosseri M, Yarom R, Gotsman MS, et al. Histologic evidence for small-vessel coronary disease in patients with angina pectoris and patent large coronary arteries. Circulation 1986;74:964-72.

20 Boden WE, Bough EW, Korr KS, et al. Exercise induced coronary spasm with ST segment depression and normal coronary arteriography. Am $\mathcal{f}$ Cardiol 1981;48: 193-7.

21 Pasternac A, Bourassa MG. Pathogenesis of chest pain in patients with normal coronary arteries. Int $f$ Cardiol patients with

22 Boudoulas $\mathrm{H}$, Cobb TC, Leighton RF, et al. Myocardial lactate production in patients with angina-like chest lactate production in patients with angina-like chest pain and angiographically normal coronary

23 James TN. Angina without coronary disease (sic). Circulation 1970;42:189-91.

24 Opherk D, Zede H, Weihe E, et al. Reduced coronary dilatory capacity and ultrastructural changes of the myocardium in patients with angina pectoris, but normal coronary arteriograms. Circulation 1981;63:817-25.

25 Cannon RO, Epstein SE. "Microvascular angina" as a cause of chest pain with angiographically normal coronary arteries. $A m$ $f$ Cardiol 1988;61:1338-43.

26 Elliot RS, Bratt G. The paradox of myocardial ischaemia and necrosis in young women with normal coronary arteriograms: relation to abnormal haemoglobin-oxygen arteriograms: relation to abnormal haemo

27 Bass C, Wade C, Hand D, et al. Patients with angina with normal and near normal coronary arteries: clinical and psychosocial state 12 months after angiography. $B M \mathcal{F}$ 1983;287:1505-8.

28 Bass C, Wade C. Chest pain with normal coronary arteries: a comparative study of psychiatric and social morbidity. Psychol Med 1984;14:51-61.

29 Romeo F, Gaspardone A, Ciavolella M, Gioffer P, Reale A. Verapamil versus acebutol for syndrome $\mathrm{X}$. $\mathrm{Am} \mathcal{F}$ Cardiol 1988;62:312-3.

30 Galassi AR, Kaski JC, Crea F, Pupita G, Gaverielides S, Tousoullis D, Maseri A. Heart rate response during exercise testing and ambulatory ECG monitoring in exercise testing and ambulatory ECG monitoring in patients

31 Bugiardini $R$. Epicardial coronary artery reactivity in patients with syndrome $X$ : the role of increased adrenergic tone. Coronary Artery Disease 1992;3:547-54.

32 Quyyumi AA, Cannon RO, Panza JA, Diodati JG, Epstein SE. Endothelial dysfunction in patients with chest pain and normal coronary arteries. Circulation 1992;86: $1864-71$.

33 Lantinga LJ, Sprafkin RP, McCroskery JH, et al. One-year psychosocial follow-up of patients with chest pain and angiographically normal arteries. $A m \mathcal{F}$ Cardiol 1988;62: 209-13.

34 Pasternak RC, Thibault GE, Savoia M, DeSanctis RW, Hutter AM. Chest pain with angiographically insignificant coronary arterial obstruction. Clinical presentation cant coronary arterial obstruction. Clinical presentato

35 Chauhan A, Mullins PA, Taylor G, et al. Syndrome X patients have abnormal cardiac nociception [abstract]. $\mathscr{f}$ Am Coll Cardiol 1993;21:450A

36 Rosano GMC, Lindsay DC, Kaski JC, Sarrel PM, PooleWilson PA. Syndrome $\mathrm{X}$ in women: the importance of the ovarian hormones [abstract]. $¥ \mathrm{Am}$ Coll Cardio 1992;19:255

37 Bugiardini R, Borghi A, Biagetti L, Puddu P. Comparison of verapamil versus propranolol therapy in syndrome $\mathrm{X}$ Am $\mathcal{f}$ Cardiol 1989;63:286-90.

38 Borghi A, Trevisani M, Saccone V, Lucarini S, Puddu GM, Bugiardini R. Resolution of symptoms does not necessarily imply remission of the disease in patients with syndrome X [abstract]. F Am Coll Cardiol 1992; with synd

39 Selzer A. Cardiac ischaemic pain in patients with normal coronary arteriograms. Am $\mathcal{F}$ Med 1977;63:661. 